MATEC Web of Conferences 47, 02010 (2016)

DOI: $10.1051 /$ matecconf/20164702010

(C) Owned by the authors, published by EDP Sciences, 2016

\title{
Average Frequency - RA Value for Reinforced Concrete Beam Strengthened with Carbon Fibre Sheet
}

\author{
M. Z. Mohamad ${ }^{1, a}$, N. Md Noor ${ }^{1}$ and W. N. A. Wan Ahmad ${ }^{1}$ \\ ${ }^{1}$ Faculty of Civil Engineering, Universiti Teknologi Mara, 13500 Permatang Pauh, Pulau Pinang, Malaysia
}

\begin{abstract}
Acoustic Emission (AE) is one of the tools that can be used to detect the crack and to classify the type of the crack of reinforced concrete (RC) structure. Dislocation or movement of the material inside the RC may release the transient elastic wave. In this situation, $\mathrm{AE}$ plays important role whereby it can be used to capture the transient elastic wave and convert it into $\mathrm{AE}$ parameters such as amplitude, count, rise time and duration. Certain parameter can be used directly to evaluate the crack behavior. But in certain cases, the AE parameter needs to add and calculate by using related formula in order to observe the behavior of the crack. Using analysis of average frequency and RA value, the crack can be classified into tensile or shear cracks. In this study, seven phases of increasing static load were used to observe the crack behavior. The beams were tested in two conditions. For the first condition, the beams were tested in original stated without strengthened with carbon fibre sheet (CFS) at the bottom of the beam or called as tension part of the beam. For the second condition, the beams were strengthened with CFS at the tension part of the beam. It was found that, beam wrapped with CFS enhanced the strength of the beams in term of maximum ultimate load. Based on the relationship between average frequency (AF) and RA value, the cracks of the beams can be classified.
\end{abstract}

\section{Introduction}

In building construction industries, reinforced concrete (RC) is usually applied for construction of foundation, beam, column and slab. Failure may take place if there is no maintenance action taken. It might be the worst moment of loss of human life [1]. Those moments can be avoided if prevention measurement takes place. In order to avoid worst cases happened, structural health monitoring (SHM) must be considered. Non-destructive test (NDT) may be used to evaluate the damage because it did not damage the structure. One of reliable technique for NDT is Acoustic Emission (AE). This technique can be used to evaluate the damage such as crack. Dislocation or fracture inside harden concrete will produce transient elastic wave [2]. This transient elastic wave can be captured by transducer and transform the transient elastic wave into electrical wave form [3]. AE parameters can be produce in $\mathrm{AE}$ data acquisition system such as count, rise time, energy, duration time and amplitude [4-6].

There are two types of analyses that can be made based on AE parameters such as parametric analyses and signal waveform analyses [4]. Md Nor et al. [2] stated that there are five types of

\footnotetext{
${ }^{a}$ Corresponding author : zakariamohamad91@gmail.com
} 
analyses can be made such as intensity analyses, b-value, RA value, calm ratio and relaxation ratio. All these kind of analyses can be used to classify the type of cracks and crack zones.

One of the methods is using average frequency (AF) versus RA value analyses (AF-RA value). The cracks can be classified into tensile crack so called as Mode Type I and shear crack so called Mode Type II [7]. Aggelis et al. [8] stated that, tensile crack or Mode Type I can be determined when the waveforms leading in faster ways together with short rise time (RT) and high rise angle. RT is the first waveform that crossing the threshold until it reaches the peak of amplitude (A). Rise angle is A per RT. It is contras if compare with shear crack whereby waveform travel slower with longer rise time and less rise of angle. Figure 1 shows the detail for tensile and shear crack according to AE waveform.

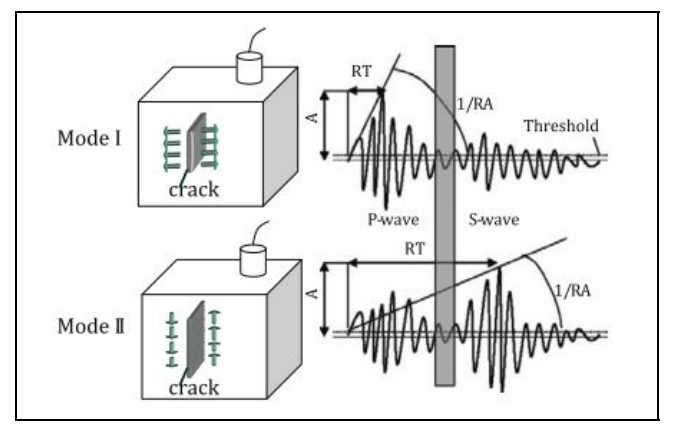

Figure 1. Detail AE waveform [8].

For the present study, two types of beam were tested and evaluated the cracks using AF-RA value analyses. One of the beams was tested in original condition with out strengthened using CFS at tension part and the rest was strengthened using 1 layer of CFS at the tension part. The AE technique and visual observation were implemented to classify the type of crack of RC beam specimen.

\section{Experimental Programme}

\subsection{Sample preparation}

Four RC bean specimens were manufactured with diamension size of $150 \mathrm{~mm}$ X $150 \mathrm{~mm}$ X $750 \mathrm{~mm}$ and classified into two types of condition. For each beam specimen, two mild steels with diameter of 8 $\mathrm{mm}$ were used at compression part and two high tensile steels were used at tension part with $6 \mathrm{~mm}$ diameter of shear link tie $100 \mathrm{~mm}$ center to center. Figure 2 shows detail reinforcement of the RC beam. The same type of beams were used as represented by Md Nor et al. [9].

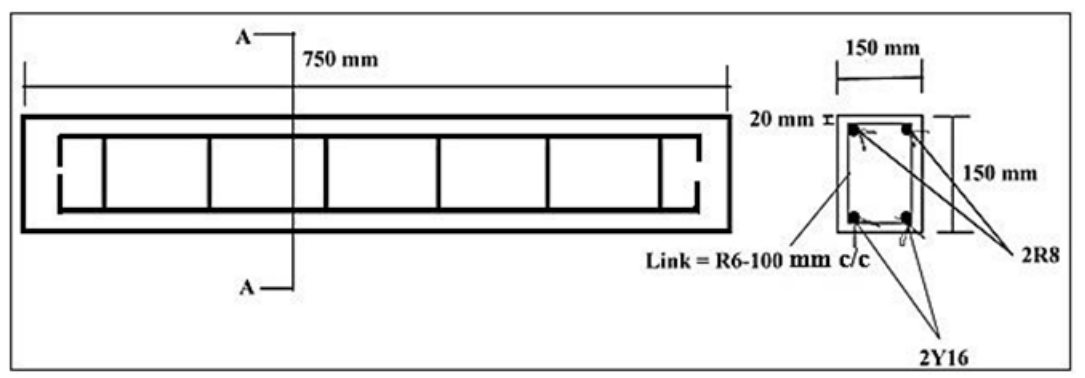

Figure 2. Detail reinforcement of RC beam. 
Each condition consists of two beam specimens. The first condition was the beam without strengthened with CFS and designated as B1 and B2. The second condition was the beam strengthened with one layer of CFS at tension part and designated as B1 1 CFS and B2 1CFS.

\subsection{Experimental work}

Three-point bending test was used to determine the ultimate load $\mathrm{P}_{\text {ult }}$ for both conditions of beams. Three-point bending was carried out using $1000 \mathrm{kN}$ UTM machine that located at heavy structure laboratory Universiti Teknologi MARA Pulau Pinang. Increasing static loads were developed based on each ultimate load. Table 1 and Table 2 show $\mathrm{P}_{\text {ult }}$ and load phases for each beam condition, respectively.

Table 1. Ultimate load for each beam condition.

\begin{tabular}{|c|c|}
\hline Beam & Average ultimate load, $\mathbf{P}_{\mathbf{u l t}}(\mathbf{k N})$ \\
\hline B1 & 114.5 \\
\hline B1 1 CFS & 138 \\
\hline
\end{tabular}

Table 2. Load phase for each condition of beam.

\begin{tabular}{|c|c|c|c|}
\hline Load phase & Load ratio & B2 (kN) & B2 2CFS (kN) \\
\hline Phase 1 & $0.1 \mathrm{P}_{\text {ult }}$ & 11.5 & 13.8 \\
\hline Phase 2 & $0.2 \mathrm{P}_{\text {ult }}$ & 23.0 & 27.6 \\
\hline Phase 3 & $0.3 \mathrm{P}_{\text {ult }}$ & 34.5 & 41.4 \\
\hline Phase 4 & $0.4 \mathrm{P}_{\text {ult }}$ & 46.0 & 55.2 \\
\hline Phase 5 & $0.5 \mathrm{P}_{\text {ult }}$ & 57.5 & 69.0 \\
\hline Phase 6 & $0.6 \mathrm{P}_{\text {ult }}$ & 69.0 & 82.8 \\
\hline Phase 7 & $0.7 \mathrm{P}_{\text {ult }}$ & 80.5 & 96.6 \\
\hline
\end{tabular}

\subsection{Af - Ra value}

Average frequency against RA value was used to determine the mitigation of crack from flexural crack to shear crack. This analyses allows characterisation of tensile crack and shear crack [7, 10]. AF is counts (CNTS) divided by the duration (D), measured in $\mathrm{kHz}$ as shown in Equation (1). RA values is the rise time (R) divided the amplitude (A), measured as shown in Equation (2).

Average frequency $=$ Counts $/$ Duration

RA values $=$ Rise time $/$ Amplitude

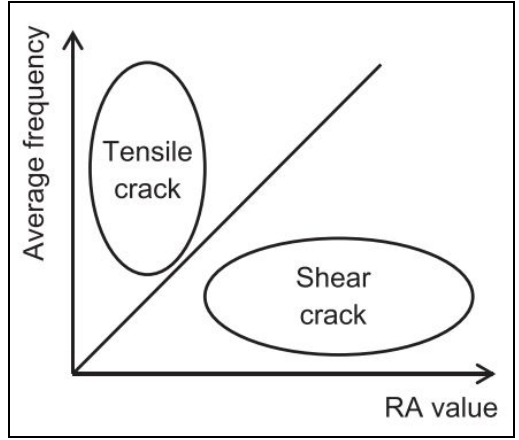

Figure 3. Location of tensile and shear crack based on AF-RA value [2]. 


\subsection{Visual observation}

Visual observation was carried out to confirm the initiation of crack and at the same to observe the type of crack [2]. Tourch light was used to confirm the initiation of crack especially hairline crack. The cracks were marked by using black marker pen for each load phase. Crack that appears was marked along the crack line and marked according to load phases.

\section{Results and Discussion}

\subsection{Comparison between B2 and B2 1CFS}

At load Phase 1 (0.1 Pult) based on Figure 4 and Figure 6, AF-RA value for B2 shows more plots at tensile zone if compared to B2 1CFS respectively. No cracks were visually observed when load Phase 1 (0.1 Pult) (see Figure 5 and Figure 7) applied on the both beams. The plots in graph AF-RA value indicate the presence of visible crack in the both beam. At this load Phase, the maximum value of 56 $\mathrm{kHz}$ than the beam B2 1CFS of $45 \mathrm{kHz}$. From these values indicate that the CFS strengthened the beam performance when load applied. At the same time, the CFS reduces the development of crack when the same load phase applied on both beams.

Based on Figure 5, the first crack appeared on the beam surface when load Phase 2 (0.2 Pult) applied for beam B2. However, for beam B2 1CFS (see Figure 7), the first crack was fully appeared on the beam surface when load Phase 3 (0.3 Pult) applied on the beam. It indicates that, the CFS attached on the soffit of the beam strengthened the beam and reduced the development of crack. At this load phase, the plots in the AF-RA value drastically increases for B2 compared to beam B2 1CFS.

Concentration of plotted point at Figure 4 higher if compared with plotted point at Figure 6 especially at tensile zone from Phase 1 until Phase 7 . For shear zone, there were less plotted point for both Figure 4 and Figure 6 even though shear crack was observed by using visually observation. From visually observation, shear crack keep happened. At the same time, concentration of plotted point at tensile zone keep increased but at shear zone it was slightly less increased. This situation happened due to tensile crack that first initiate before it continues to transform into shear crack [14]. It can be conclude that the shear developed through extension of flexural crack for RC beam specimen without strengthened with CFS.
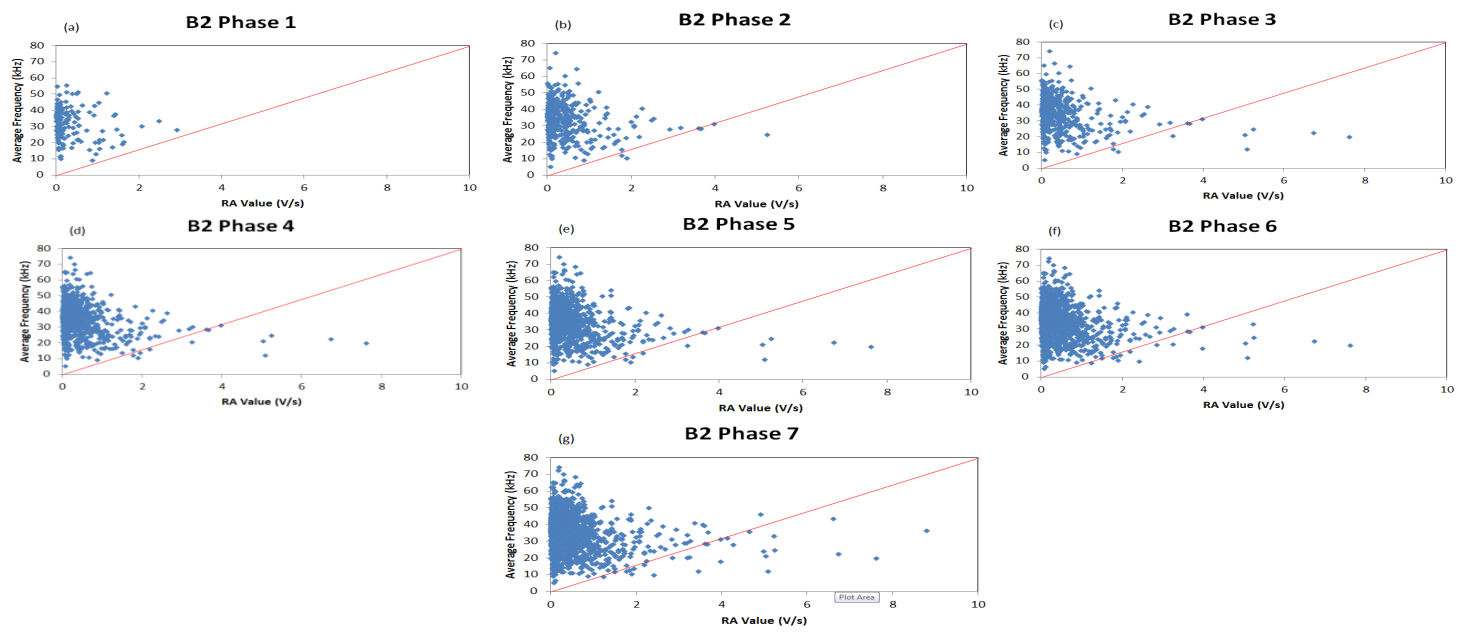

Figure 4. Relationship between average frequency and RA value for Beam B2 (a) Phase $1\left(0.1 \mathrm{P}_{\mathrm{ult}}\right)$, (b) Phase 2 $\left(0.2 \mathrm{P}_{\text {ult }}\right)$, (c) Phase $3\left(0.3 \mathrm{P}_{\text {ult }}\right)$, (d) Phase $4\left(0.4 \mathrm{P}_{\text {ult }}\right)$, (e) Phase $5\left(0.5 \mathrm{P}_{\text {ult }}\right)$, (f) Phase $6\left(0.6 \mathrm{P}_{\text {ult }}\right)$ and $(\mathrm{g})$ Phase 7 $\left(0.7 \mathrm{P}_{\mathrm{ult}}\right)$ 


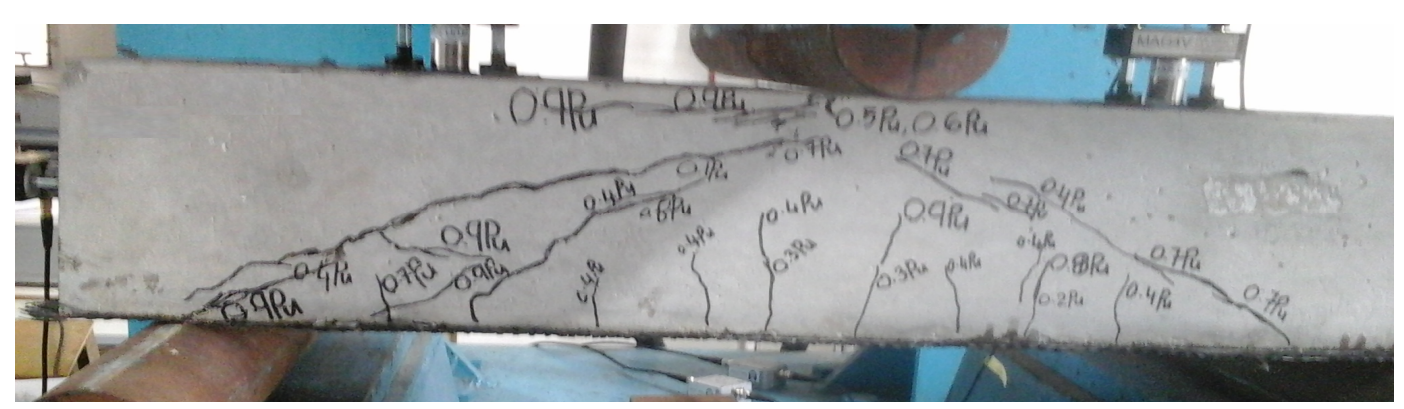

Figure 5. Crack pattern of RC beam specimen without strengthened with CFS on the soffit
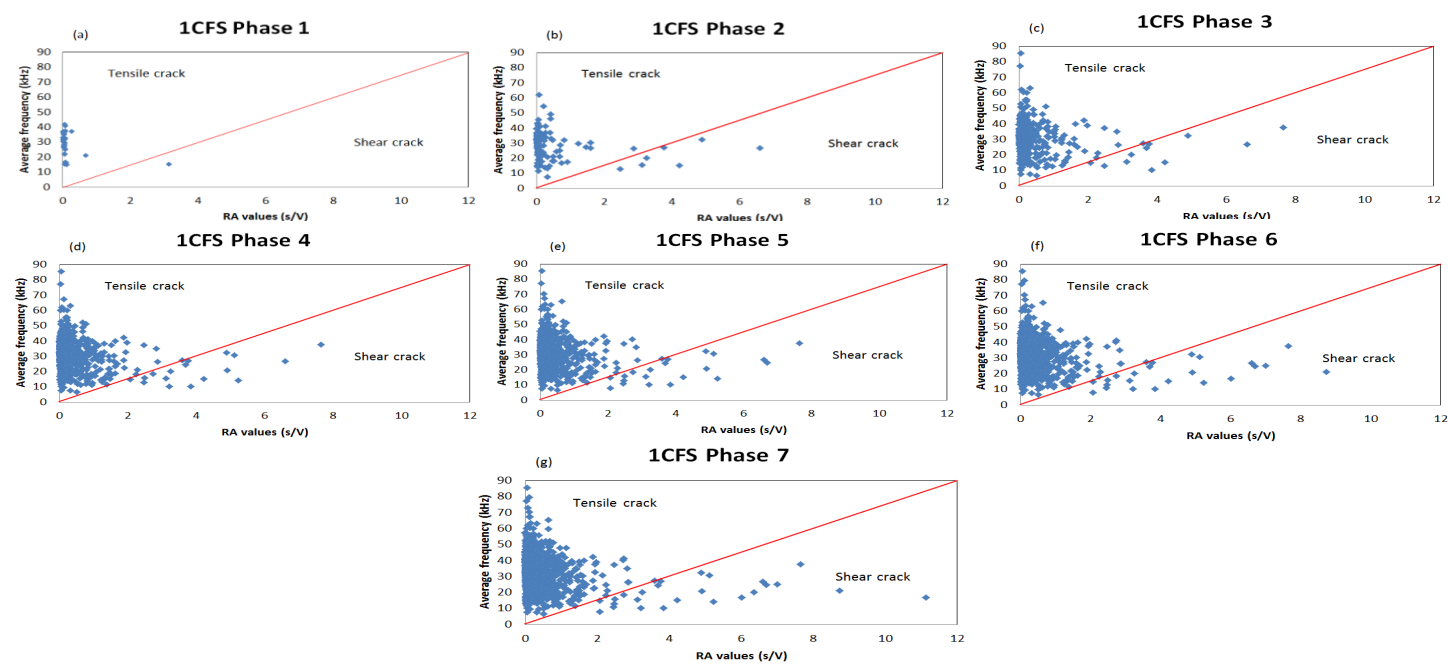

Figure 6. Relationship between average frequency and RA value for Beam B2 1CFS (a) Phase 1 (0.1 Pult), (b) Phase 2 (0.2 Pult), (c) Phase 3 (0.3 Pult), (d) Phase 4 (0.4 Pult), (e) Phase 5 (0.5 Pult), (f) Phase 6 (0.6 Pult) and (g) Phase 7 (0.7 Pult).

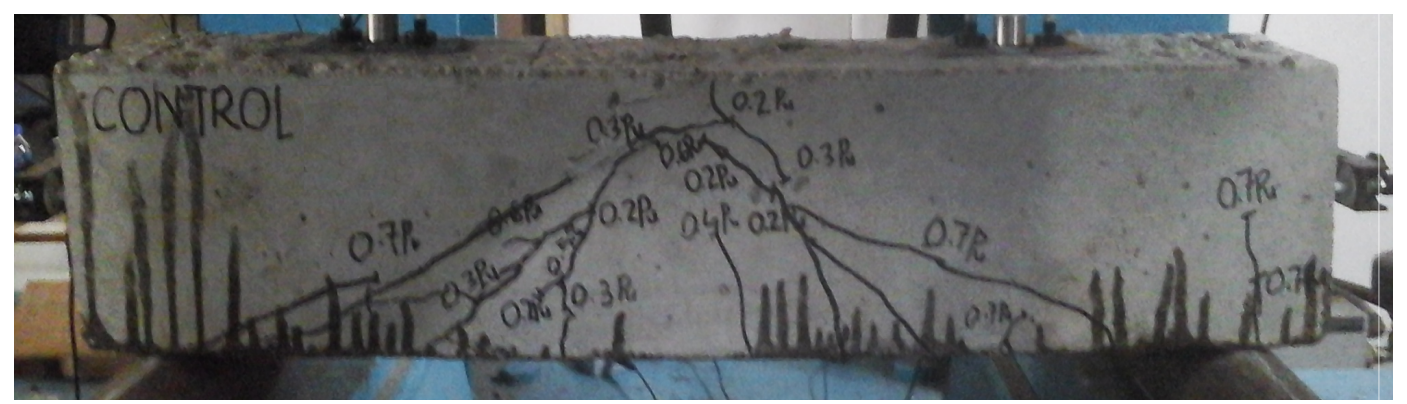

Figure 7. Crack pattern of RC beam specimen strengthened with CFS on the soffit.

\section{Conclusion}

The relationship between AF and RA value from AE signal collected from channel 6 was investigated. The crack classifications of RC beam specimen with and without strengthened using CFS on the soffit were identified. Two types of cracks namely tensile crack and shear crack were recognized. The result 
from the relationship between AF and RA value are well matched with the crack pattern appeared on the RC beam surface. At the early stage, AF-RA value graph shows the concentration of plots at tensile zone for both types of $\mathrm{RC}$ beams and no crack was visually observed. This situation happened at Phase 1 for B2 and Phase 1 until Phase 2 for B2 1CFS. The plots might be from the invisible crack that cannot be seen by naked eyes. First initiation of crack happened at Phase 2 for B2 and Phase 3 for B2 1CFS. The crack start to transform into shear crack at Phase 2 for B2 and Phase 4 for B2 1CFS. Shear crack occurred due to increasing of static load. This indicates that shear crack is extension process from tensile crack. This shows that, AF-RA value can be used to evaluate type of crack according to increment of loading phase. Overall, the attachment of CFS on the soffit reduces the development of crack in the RC beam.

\section{References}

1. M.R. Esfahani, M.R. Kianoush and A.R. Tajari, Flexural behaviour of reinforced concrete beams strengthened by CFRP sheets, Engineering Structures, 29, 2428-2444, (2007)

2. N. Md Nor, A. Ibrahim, N. Muhamad Bunnori and H. Mohd Saman, Acoustic emission signal for fatigue crack classification on reinforced concrete beam, Construction and Building Materials, 49, 583-590, (2013)

3. D.G. Aggelis, Classification of cracking mode in concrete by acoustic emission parameters, Mechanics Research Communications, 38(3), 153-157, (2011)

4. A. Behnia, H.K. Chai and T. Shiotani, Advanced structural health monitoring of concrete structures with the aid of acoustic emission, Construction and Building Materials, 65, 282-302, (2014)

5. J. Lee and J. Lee, Non-destructive evaluation on damage of carbon fiber sheet reinforced concrete, Composite Structures, 58, 139-147, (2002)

6. G. Ma, H. Li, M. Asce and Z. Duan, Repair effects and acoustic emission technique-based fracture evaluation for predamaged concrete columns confined with fiber-reinforced polymers, J. of Composites for Construction, 16(6), 626-639, (2012)

7. S. Shahidan, R. Pullin, K.M. Holford, N.M. Bunnori and N.M. Noor, Quantitative evaluation of the relationship between tensile crack and shear movement in concrete beams, Advanced Materials Research, 626, 355-359, (2012)

8. D.G. Aggelis, A.C. Mpalaskas, D. Ntalakas and T.E. Matikas, Effect of wave distortion on acoustic emission characterization of cementitious materials, Construction and Building Materials, 35, 183-190, (2012)

9. N. Md Nor, A. Ibrahim, N. Muhamad Bunnori, H.M. Saman, S.N. Mat Saliah and S. Shahidan, Diagnostic of fatigue damage severity on reinforced concrete beam using acoustic emission technique, Engineering Failure Analysis, 41, 1-9, (2014)

10. M. Ohtsu, T. Isoda and Y. Tomoda, Acoustic emission techniques standardized for concrete structures, J. Acoustic Emission, 25, 21-32, (2007)

11. T. J. Hadzor, R.W. Barnes, P.H. Ziehl, J. Xu and A.K. Schindler, Development of acoustic emission evaluation method for repaired, Highway Research Center, (2011)

12. M.A.A. Aldahdooh, N.M. Bunnori and M.A. Megat Johari, Damage evaluation of reinforced concrete beams with varying thickness using the acoustic emission technique, Construction and Building Materials, 44, 812-821, (2013)

13. B.B. Adhikary and H. Mutsuyoshi, Behavior of concrete beams strengthened in shear with carbon-fiber sheets, J. of Composites for Construction, 8, 258-264, (2004)

14. N. Md Nor, A. Ibrahim, N.M. Bunnori, H.M. Saman, S. Noor, M. Saliah and S. Shahidan, Fatigue crack inspection and acoustic emission characteristics of precast RC beam under repetition loading, 774, 1022-1026, (2015) 